\title{
Commentary Neuroimmune perspectives in sepsis
} Luis Ulloa and Edwin A Deitch

Department of Surgery, UMDNJ - New Jersey Medical School, 185 South Orange Avenue, PO Box 1709, Newark, NJ 07103, USA

Corresponding author: Luis Ulloa, Mail@LuisUlloa.com

Published: 23 April 2009

This article is online at http://ccforum.com/content/13/2/133

(c) 2009 BioMed Central Ltd

See related research by Hofer et al., http://ccforum.com/content/13/1/R11
Critical Care 2009, 13:133 (doi:10.1186/cc7758)

The studies of Hofer and colleagues suggest that central sympatholytics may control systemic inflammation by inhibiting NF-KB and cytokine production in the liver [1]. If the vagus nerve mediates the anti-inflammatory potential of the $\alpha_{2}$-agonists, however, central sympatholytics may modulate systemic inflammation through a mechanism mediated by the spleen [4]. Recent studies indicate that the spleen is a major source of inflammatory cytokines in experimental sepsis, as splenectomy attenuates systemic inflammation and protects against sepsis. The spleen is required for the antiinflammatory potential of the vagus nerve. Vagus nerve stimulation inhibits systemic TNF levels in control animals but not in splenectomized animals [5]. Likewise, nicotinic agonists prevent systemic inflammation and improve survival in control animals but not in splenectomized animals. These studies might have clinical implications as they may not be beneficial for patients with a compromised or damaged spleen.

Rosas-Ballina and colleagues have recently demonstrated that there is no cholinergic connection between the vagus nerve and immune cells in the spleen [6]. The vagus nerve does not innervate the spleen, and vagal immunomodulation in experimental sepsis is mediated by postganglionic catecholaminergic fibers from the celiac mesenteric plexus traveling through the splenic nerve [6]. Unlike central-acting drugs, peripheral sympatholytics can prevent the antiinflammatory potential of the vagus nerve and enhance systemic inflammation in sepsis.

Can NF- $\mathrm{kB}$ predict the outcome of sepsis? Since NF-KB is a key regulator of cytokine production, NF-kB inhibition can modulate systemic inflammation [4]. A characteristic example is that the protection of RAGE-deficient mice from sepsis correlates with NF-KB inactivation in the lung and peritoneum. $\mathrm{NF}-\mathrm{kB}$, however, also protects parenchyma cells from

$\mathrm{CLP}=$ cecal ligation and puncture; NF = nuclear factor; TNF = tumor necrosis factor. 
cytotoxicity and cell death $[7,8]$. The most characteristic example is that p65RelA and IKK knockout mice exhibit embryonic death resulting from extensive TNF $\alpha$-mediated fetal hepatocyte apoptosis. Consistently, disruption of TNF $\alpha$ signaling - either by removing TNF $\alpha$ or TNF receptor 1 prevents this hepatocyte apoptosis in rela-l- mice, allowing embryonic development to birth. In agreement with these studies, inhibition of NF- $\mathrm{kB}$ after partial hepatectomy results in massive hepatocyte apoptosis and impairs liver function. Conversely, NF- $\mathrm{KB}$ activation in the liver prevents hepatic injury during ischemia and reperfusion. NF- $\mathrm{KB}$ inhibition produces different effects in enterocytes, however, and can prevent intestinal derangements during sepsis. These studies suggest that the ubiquitous inhibition of NF-KB may not generate an overall beneficial effect especially in the liver, unless the therapy targets specific organs or immune cells. Future studies are needed to determine the molecular and cellular mechanism by which central sympatholytics modulate the different NF- $\kappa B$ pathways in sepsis.

What is the therapeutic time frame for experimental sepsis? Pre-emptive treatment with central sympatholytics started 12 hours before cecal ligation and puncture (CLP) provides survival benefits, but not if the treatment was started 1 hour after the surgical procedure [1]. One potential explanation for this is that the early phase of sepsis is characterized by high concentrations of circulating catecholamines, which can boost the initial inflammatory responses. The endogenous production of catecholamines decreases during the progression of sepsis, however, and can become insufficient for the homeostasis of the cardiovascular system (as indicated by the need for catecholamine administration during septic shock) [9]. Late inhibition of catecholamines can therefore be rather detrimental. Another consideration is that ketamine, the anesthetic used for CLP surgery by Hofer and colleagues, is a noncompetitive inhibitor of nicotinic receptors that can limit the anti-inflammatory potential of the vagus nerve. Since the half-life of ketamine is approximately 3 hours, this anesthetic may limit the effect of sympatholytics administered 1 hour after the CLP.

Previous studies from Hofer and colleagues also indicate that pharmacologic cholinesterase inhibition with physostigmine or neostigmine improved survival in experimental sepsis when the treatment was started immediately after the CLP [10]. A significant trend toward protection was observed when the treatment was started 6 hours after the surgical procedure. Yet the authors noted this protection was not statistically significant $(P=0.057)$, probably due to the small sample size [10]. An important consideration is that these strategies can be limited by a potential cholinergic attrition that limits acetylcholine production by the vagus nerve during sepsis. Since vagus nerve stimulation requires $\alpha_{7}$-nicotinic acetylcholine receptors, direct activation of this receptor using nicotinic agonists may prevent this potential cholinergic attrition during the progression of sepsis. Indeed, nicotine improved survival in experimental sepsis even when the treatment was delayed 24 hours after CLP [11]. Similar results have been confirmed by other investigators using selective $\alpha_{7}$-nicotinic acetylcholine receptor agonists. On the other hand, there are significant differences in these studies that can contribute to these late therapeutic benefits. The two studies use different models of sepsis (with or without antibiotics) and mice with different gender, age and genetic background (female C57BL/6 mice 12 to 16 weeks old versus male BALB/c mice 6 to 8 weeks old). Hofer and colleagues do not use antibiotics to prevent their interferences with the immune responses [1], whereas Wang and colleagues used antibiotics to mimic clinical settings [11]. It is possible that the use of antibiotics may limit bacteremia induced by CLP and may favor the benefits of delayed treatment with nicotinic agonists.

Future studies are needed to determine the therapeutic time window of central sympatholytics and how this window may be affected by genetic background, sex, gender and antibiotics both in clinical and experimental models.

\section{Competing interests}

The authors declare that they have no competing interests..

\section{Acknowledgements}

LU is supported by the faculty program of the Department of Surgery of the New Jersey Medical School, and grants from the US Army Medical Research Command (USAMRMC\#05308004), the American Heart Association (AHA06352230N), and the NIH (RO1-GM084125).

\section{References}

1. Hofer S, Steppan J, Wagner T, Funke B, Lichtenstern C, Martin E, Graf BM, Bierhaus A, Weigand MA: Central sympatholytics prolong survival in experimental sepsis. Criti Care 2009, 13: R11.

2. Pandharipande PP, Pun BT, Herr DL, Maze M, Girard TD, Miller RR, Shintani AK, Thompson JL, Jackson JC, Deppen SA, Stiles RA, Dittus RS, Bernard GR, Ely EW: Effect of sedation with dexmedetomidine vs lorazepam on acute brain dysfunction in mechanically ventilated patients: the MENDS randomized controlled trial. JAMA 2007, 298:2644-2653.

3. Ulloa $L$ : The vagus nerve and the nicotinic anti-inflammatory pathway. Nat Rev 2005, 4:673-684.

4. Ulloa L, Brunner M, Ramos L, Deitch EA: Scientific and clinical challenges in sepsis. Curr Pharm Des 2009, in press.

5. Huston JM, Ochani M, Rosas-Ballina M, Liao H, Ochani K, Pavlov VA, Gallowitsch-Puerta M, Ashok M, Czura CJ, Foxwell B, Tracey $\mathrm{KJ}$, Ulloa L: Splenectomy inactivates the cholinergic antiinflammatory pathway during lethal endotoxemia and polymicrobial sepsis. J Exp Med 2006, 203:1623-1628.

6. Rosas-Ballina M, Ochani M, Parrish WR, Ochani K, Harris YT, Huston JM, Chavan S, Tracey KJ: Splenic nerve is required for cholinergic antiinflammatory pathway control of TNF in endotoxemia. Proc Natl Acad Sci U S A 2008, 105:11008-11013.

7. Gerondakis S, Grumont R, Gugasyan R, Wong L, Isomura I, Ho $\mathrm{W}$, Banerjee A: Unravelling the complexities of the NF- $\mathrm{kB}$ signalling pathway using mouse knockout and transgenic models. Oncogene 2006, 25:6781-6799.

8. Beg AA, Sha WC, Bronson RT, Ghosh S, Baltimore D: Embryonic lethality and liver degeneration in mice lacking the RelA component of NF-кB. Nature 1995, 376:167-170.

9. Rittirsch D, Flierl MA, Ward PA: Harmful molecular mechanisms in sepsis. Nat Rev Immuno/ 2008, 8:776-787.

10. Hofer S, Eisenbach C, Lukic IK, Schneider L, Bode K, Brueckmann M, Mautner S, Wente MN, Encke J, Werner J, Dalpke AH, Stremmel W, Nawroth PP, Martin E, Krammer PH, Bierhaus A, 
Weigand MA: Pharmacologic cholinesterase inhibition improves survival in experimental sepsis. Crit Care Med 2008, 36:404-408.

11. Wang $\mathrm{H}$, Liao $\mathrm{H}$, Ochani $M$, Justiniani $M$, Lin $X$, Yang L, Al-Abed $Y$, Wang H, Metz C, Miller EJ, Tracey KJ, Ulloa L: Cholinergic agonists inhibit HMGB1 release and improve survival in experimental sepsis. Nat Med 2004, 10:1216-1221. 